\title{
Orientações para o uso do Novo Testamento Grego
}

\author{
Antônio Renato Gusso
}

ALAND, Kurt; ALAND, Barbara. O texto do Novo Testamento: Introdução às edições científicas do Novo Testamento Grego bem como à prática da moderna crítica textual. Barueri, SP: Sociedade Bíblica do Brasil, 2013, 384p.

Este não é um livro simples, que possa ser lido em pouco tempo e de maneira descontraída. Na verdade, ele é quase um manual para consulta, extremamente técnico e bem direcionado, voltado para aqueles que desejam utilizar o Novo Testamento Grego em suas versões chamadas de "Novum Testamentum Graece", também conhecida como "Nestle-Alan", e "O Novo Testamento Grego", com edição já publicada no Brasil, pela Sociedade Bíblica do Brasil, desde 2009, com introduções em português, o que foi um grande avanço para os estudantes e pesquisadores brasileiros envolvidos com este assunto. Sua leitura deve ser feita de forma paciente e cuidadosa, com os textos gregos em mãos para conferência e melhor aproveitamento.

A obra também não é nova. Ela foi produzida pelo erudito Kurt Aland, especialista em história da igreja e crítica textual, falecido em 1994, contando com a colaboração de sua esposa Barbara Aland, a qual continuou o trabalho do esposo como diretora do Instituto de Pesquisa Textual do Novo Testamento, em Münster, na Alemanha, até sua aposentadoria em 2004. A obra foi publicada no início da década de oitenta, em alemão, com o título "Der Text der Neuen Testaments", e teve duas edições nesta língua antes de ser traduzida 
para o inglês, em 1987, por Errol F. Rhodes. Contudo, ainda que não se possa dizer que ela seja nova (No Brasil é novíssima, pois foi lançada neste ano de 2013), pode-se afirmar que ela contém novidades e está, razoavelmente, atualizada. Seu tradutor, Vilson Schols, não só traduziu o texto que recebeu, mas o adaptou, dentro das suas possibilidades, à realidade atual. Neste trabalho de adaptação é destacada a atualização dos dados da $26^{a}$ edição do "Nestle-Aland", para a 27 a , e a do "Novo Testamento Grego", da $3^{\mathrm{a}}$ edição, utilizada no original de Kurt e Barbara, para a $4^{\mathrm{a}}$ edição, a que tem estado à disposição dos estudiosos na atualidade.

O tradudor/adaptador explica a razão pela qual não fez a devida atualização para a 28 a edição de "Nestle-Aland", lançada em 2012. De acordo com a informação dele mesmo, o livro em português já estava terminado quando surgiu esta nova edição crítica do Novo Testamento Grego. Ele também explica que a $28^{a}$ edição é nova, no que diz respeito ao texto, apenas nas Epístolas Católicas, onde ocorreram pouco mais de 30 alterações, o que é pouco, no entendimento dele. Ainda, segundo o tradutor, as alterações de destaque foram feitas no aparato crítico, procurando, em especial, simplificar o seu uso. Ou seja, a $28^{\mathrm{a}}$ edição de "Nestle Aland", ainda que importante, é praticamente igual à sua edição anterior. Ele ainda destaca que a sua tradução foi feita diretamente do texto alemão, mas com consultas, em determinados pontos, à versão inglesa.

O conteúdo do livro é apresentado em oito capítulos que merecem ter seus títulos aqui citados para melhor informar os leitores a respeito do que pode encontrar em suas páginas. São eles: 1) As edições do Novo Testamento Grego (Relato histórico dividido em quatro períodos assim denominados: De Erasmo até Griesbach, de Lachmann até Nestle, do Antigo Nestle ao novo Nestle, comparação entre as mais importantes edições); 2) A transmissão do Novo Testamento Grego; 3) Os Manuscritos do Novo Testamento Grego; 4) As traduções antigas do Novo Testamento (Com destaque para aquelas que foram traduzidas diretamente do grego ou foram cuidadosamente revisadas com base nele); 5) Introdução ao uso das edições modernas do Novo Testamento Grego (Com orientações práticas para que o leitor consiga "decifrar" as orientações dos aparatos críticos); 6) Recursos (Concordâncias, dicionários, gramáticas, sinopses, livros técnicos e comentários, apresentados nesta sequência, que para os autores segue a ordem de importância que possuem em relação ao trabalho de crítica textual); 7) Introdução à prática da crítica textual do Novo Testamento com base em exemplos selecionados; e 8) Adendos, em 
duas partes: a) Texto e valor textual dos manuscritos do Novo Testamento: um novo instrumento de trabalho e um método para a avaliação de toda a transmissão textual do Novo Testamento (trata-se de uma palestra de Barbara Aland, apresentada em Birmingham, em setembro de 1987); e b) Categorias e tipos de texto.

A apresentação do livro é muito boa; ele foi impresso em papel de ótima qualidade e possui capa dura. Infelizmente foi impresso em letras um tanto quanto miúdas, dificultando a leitura para boa parte dos leitores que se interessam por este assunto, os quais, normalmente, já têm uma longa história de estudos realizados e, em consequência do tempo que isso exige, também não são muito jovens. Ele possui dois prefácios, o primeiro correspondente às informações gerais escritas pelos autores, com referências às edições em alemão e, o segundo, escrito pelo tradutor para o português. Tem: um índice das quarenta e cinco figuras utilizadas no livro, (São quadros, gráficos, textos de versões, e, em destaque, fotos de manuscritos), um índice de nomes e assuntos e, ainda, um índice de referências, o qual se mostra muito útil para o estudante que deseja consultar textos bíblicos, em particular os que foram tratados na obra. Diga-se de passagem, um dos pontos fortes da obra é, exatamente, a apresentação de exemplos tratados no texto bíblico.

Algumas das partes deste livro são de compreensão inatingível para algum leigo no assunto que, por ventura, se lance à sua leitura. Em especial, pode-se destacar o primeiro capítulo, uma história das edições do Novo Testamento Grego, e as vastas porções que identificam os manuscritos que fazem parte dos aparatos críticos das edições do Novo Testamento Grego tratadas na obra, como, por exemplo, a lista descritiva dos minúsculos, a qual ocupa cerca de vinte páginas, algumas delas contendo apenas os números de tais manuscritos. Diante desta infinidade de informações, pode ajudar o pesquisador a orientação dada a respeito da importância dos manuscritos. Ainda que cada um deles tenha a sua importância e por isso se encontre nos aparatos críticos, os que possuem relevância automática são aqueles que pertencem, pelo menos, ao período que vai da passagem do terceiro para o quarto século, época anterior à formação dos grandes textos (p.245).

A obra é importante para o tradutor e exegeta, e foi escrita tendo-se este público alvo em vista, mas não é útil apenas para este grupo, pois também possui partes que podem interessar ao historiador eclesiástico e outros interessados na história da Igreja. Dentro desta classificação estão duas listas muito interessantes: a lista descritiva dos Pais Eclesiásticos gregos (p.183-188) e a 
lista descritiva dos Pais Latinos e Orientais (p.217-222), que aparecem em destaque no aparato crítico da $27^{\mathrm{a}}$ edição de "Nestle-Aland" e, principalmente, na 4 a edição de "O Novo Testamento Grego". O leitor, pesquisador, que trabalha com estas edições do Novo Testamento Grego, ao encontrar uma referência a um destes pais, pode fazer uma consulta rápida a esta lista e ficar sabendo um pouco mais do que apenas o nome da autoridade citada e a data aproximada de sua morte, como as edições do Novo Testamento Grego informam. Nela encontrará informações a respeito da época da vida do personagem bem como alguns destaques sobre a sua atuação, conversão ao cristianismo, posição na Igreja, quando é o caso, e obra realizada, entre outras.

Um exemplo interessante dos nomes nesta lista pode ser o do Pai Latino Lúcifer de Cagliari. Com certeza este nome não é comum nos dias atuais pela ligação que foi feita dele (do nome, não do Pai Latino) com Satanás. Contudo, vendo nesta lista este nome atribuído a um dos Pais Latinos, não fica difícil de compreender que, na época de sua atuação, este era um nome, no mínimo, muito bem aceito. O livro mostra que ele é citado no aparato crítico com a indicação $L c f$, a qual deve ser entendida como Lúcifer, mas no próprio aparato não aparece mais nenhuma informação a respeito dele, o que pode causar estranheza para o leitor menos conhecedor da História Eclesiástica. Na introdução da $4^{\mathrm{a}}$ edição de "O Novo Testamento Grego" aparece apenas o nome deste Pai da Igreja e o presumido ano de sua morte, mas, na lista dos Pais Latinos, apresentada neste livro, ele é citado, ainda que de forma resumida, como o tipo de texto exige, da seguinte e esclarecedora maneira: "Lúcifer de Cagliari (Lcf) - Faleceu em 370 ou 371. Bispo de Cagliari (Sardenha). Depois do Sínodo de Milão (355), viveu no exílio. Desse tempo são os seus escritos polêmicos, que, com as suas citações bíblicas, são importantes para o texto do tempo anterior a Jerônimo (p.219)".

Uma demonstração bastante prática aparece na p.225, a qual orienta o leitor a respeito do propósito de cada uma das edições do Novo Testamento Grego abordadas na obra. De acordo com os autores " $O$ Novo Testamento Grego" tem em vista os tradutores, enquanto o "Nestle-Aland" está voltado mais para professores, intérpretes do Novo Testamento e estudantes de teologia. Segundo eles, muitos também preferem "O Novo Testamento Grego" e não o "Nestle-Aland", devido à maior complexidade do aparato crítico deste segundo. Esta fama de complexidade é contestada pelos autores que destacam que o sistema é formado por apenas sete sinais ou símbolos que devem ser decorados, chamados por eles de sinais de fácil memorização (p.232-233), 
ainda que, na prática, não seja bem isso que se possa verificar entre os principiantes no estudo deste tema.

Com certeza os professores de exegese vão gostar do Capítulo VII, "Introdução à prática da crítica textual do Novo Testamento com base em exemplos selecionados". Esta parte é um bom instrumento de exegese que, com a ajuda do Índice de Referências, pode ser bem aproveitada para exercícios particulares e em sala de aula. Talvez seja desnecessário, pela temática da obra, mas nunca é demais avisar, o livro não tem como ser lido, em muitas de suas partes, por leitores que desconheçam o grego bíblico. No geral, para encerrar esta resenha, pode-se dizer: Finalmente, ainda que com décadas de atraso, chegou ao Brasil, em língua portuguesa, uma obra de peso, que, provavelmente, se tornará referência para estudantes, professores, exegetas e tradutores do Novo Testamento Grego.

\author{
Antônio Renato Gusso \\ Doutor em Teologia, pelo STBS \\ Doutor em Ciências da Religião, pela UMESP \\ Pós-doutor em Teologia, pela EST \\ Professor na Faculdade Batista Pioneira \\ Professor e Coordenador de Mestrado em Teologia na \\ Faculdade Teológica Batista do Paraná \\ Brasil \\ E-mail: renatogusso@hotmail.com
}

Recebido em 02/12/13

Aprovado em 03/12/13 